\title{
Article \\ Postural Risk in Manual Planting Operations of Poplar: Two Options Compared
}

\author{
Tiberiu Marogel-Popa, Marina Viorela Marcu and Stelian Alexandru Borz * \\ Department of Forest Engineering, Forest Management Planning and Terrestrial Measurements, \\ Faculty of Silviculture and Forest Engineering, Transilvania University of Braşov, Şirul Beethoven No.1, \\ 500123 Braşov, Romania; marogel@unitbv.ro (T.M.-P.); viorela.marcu@unitbv.ro (M.V.M.) \\ * Correspondence: stelian.borz@unitbv.ro; Tel.: +40-742-042-455
}

Received: 5 June 2020; Accepted: 6 July 2020; Published: 9 July 2020

\begin{abstract}
Poplar forests are cultivated worldwide on extended areas, contributing to the provision of wood for industries. Their management is intensive, especially in planting operations which are done, in many parts of the world, by the use of manual labor. This situation raises the question on their sustainability from an ergonomics point of view. Particularly, the postural risk is in question, as uncomfortable work postures may cause musculo-skeletal disorders. Two types of planting operations (large cutting- $\mathrm{CP}$ and bare-root seedling- $\mathrm{SP}$ ) were selected as representatives for the evaluation of postural risks which was carried out for 14 subjects. Based on the analysis of approximately 14,500 images (approximately $67 \mathrm{~h}$ of field study), the postural risk indexes were estimated at 259 and 250 for the CP and SP, respectively. No significant differences were found between the operations, but the high share of effective planting tasks and their associated postural risk indexes generated these concerning results. The main conclusion is that these kinds of planting operations need postural improvement and ways for doing so should be researched in the future.
\end{abstract}

Keywords: agro-forestry operations; poplar planting; manual labor; postural risk; OWAS method; sustainability; reengineering; improvement

\section{Introduction}

The cultivated poplar forests stand for a valuable source of wood for industrial and individual house-hold use, and they hold an important potential to contribute to the satisfaction of the increasing demand of lignocellulosic raw materials. They are cultivated on extended areas [1,2] using fast-growing trees by operations which could be regarded as being more labor intensive compared to those specific to the traditional close-to-nature management of forests; that's because the typical sequence includes soil preparation, planting, fertilization, irrigation, and weed control operations [3], which are followed by regular harvesting operations such as thinning and clear-cutting [4]. Among these, planting is crucial in the operational management because on its quality and timely implementation depends the success of new forests [5].

Depending on the local forest management, terrain morphology, and the available technology, to name just few factors, planting of forests may be implemented either by mechanized [6,7], partly mechanized [8,9], or manual operations solely [5]. In Romania, as well as in other Eastern European countries, partly mechanized systems are still dominating the scene of forest operations [10]. This applies also to the planting operations of fast-growing poplar forests where the use of manual labor is still intensive. As such, at least problems in the sphere of ergonomics may arise, especially in the context in which many operations are still carried out manually around the world, and they have been proven to be physically demanding [11]. Therefore, scientific information is still required to engineer the operations to an extent which will ensure their sustainability. This approach is congruent 
with recent research that describes the main pillars of sustainability in forest operations $[12,13]$, with the ergonomics and risk awareness being among them [12]. In particular, exposure to risks of developing musculo-skeletal disorders may be one of the most critical currently-faced problems of manual work, especially in forest operations, which are developed outdoors and are generally recognized to be among the most difficult ones [14].

A particular area of research in ergonomics is that referring to postural analysis which has provided important means and ways for research and improvement, enabling attempts to ensure the sustainability of various industrial sectors. As such, several methods were developed, validated, and used in time to evaluate the postural status-quo of different operations and to take corrective measures [15]. Such approaches are of invaluable importance since the musculoskeletal disorders (MSDs) are seen nowadays to be the most common cause of severe pain and physical disability, which in turn have important negative economic effects [16]; therefore, targeted studies have been conducted in many sectors, showing a strong relation between work factors and tasks and the development of MSDs. From these points of view, it seems that manual planting operations have received less attention by scientific research in the area of postural assessment. However, it is likely for manual planters to face awkward working postures given the tasks they are required to undertake. Such postures may refer to frequent situations in which the workers may hold their back bent and twisted, as well as to tasks requiring working with the knees bent. For instance, the Romanian standards describe working tasks that have an increased potential to generate deviant working postures in seedling planting operations [17]. In addition, the Romanian technique of poplar planting which uses large poplar cuttings, may generate unsustainable situations from a postural point of view given the size of planting material and the ways used to handle and plant it into the pits. Both techniques have been proven to be very intensive from the point of view of cardiovascular workload [9], and this outcome has provided some hints on the potential postural difficulties, given the fact that body posture changes are causing an increased cardiovascular activity [18-20]. However, the postures themselves adopted during the work may not be the sole drivers of an increased cardiovascular workload while they could inflict other problems related to the health of workers. In our knowledge, postural assessments have not been carried out for the typical case of manual poplar planting operations.

Based on the above, the main goal of this study was to characterize, from a postural assessment point of view, the manual planting operations of poplar forests to be able to set the stage for their improvement. Two types of planting operations were selected for this study (large cutting planting and bare-root seedling planting) and the objectives were set to: (i) describing and characterizing the distribution of tasks per subjects and type of operations, (ii) describing and characterizing postural risks on subjects, tasks, and type of operations, and (iii) comparing at task and operation type level the postural risks as specific to the two planting options taken into study.

\section{Materials and Methods}

\subsection{Study Location and Planting Material}

The Romanian cultivated poplar forests are dominantly established in flatlands, and they are harvested at the age of 25 years. It is typical that planting operations for them are undertaken by a two-pass system [17]. As such, in a first pass, regular farming tractors equipped with drilling devices are used to configure the planting pits at the dimensions required to plant either large cuttings or bare-root seedlings. From this point of view, the option used depends on the poplar species to be planted [5]. Specific to the studied conditions was that the first option required pits having approximately $2 \mathrm{~m}$ in depth and $0.2 \mathrm{~m}$ in diameter; the second option required pits of $0.6 \mathrm{~m}$ in depth and $0.6 \mathrm{~m}$ in diameter. Then, in a second pass, the effective planting operations were carried out exclusively by manual labor. As the scope of this study was the manual planting operations, field observations were carried out during November and December of 2018 in eight planting sites (hereafter L1 to L8) which were chosen based on representativity criteria of the operations taken into study (Table 1). By doing so, 
the aim was to cover the variability given by the planting schemes and the planting material used. Two poplar species have been used in operations, namely Populus $\times$ canadensis, which is a hybrid poplar, (hereafter PLEA), and Populus alba (hereafter PLA), respectively. These two species are commonly used in the study area (Dolj county) and in Romania to establish fast-growing poplar forests [21].

Table 1. Description of planting sites, species used, planting scheme, and planting material. PLEA: Populus $\times$ canadensis. PLA: Populus alba.

\begin{tabular}{|c|c|c|c|c|c|c|}
\hline $\begin{array}{c}\text { Study } \\
\text { Location }\end{array}$ & $\begin{array}{l}\text { Forest } \\
\text { District }\end{array}$ & $\begin{array}{l}\text { Geographical } \\
\text { Coordinates }\end{array}$ & $\begin{array}{l}\text { Forest Compartment } \\
\text { and Its Area (ha) }\end{array}$ & $\begin{array}{l}\text { Species } \\
\text { Used }\end{array}$ & $\begin{array}{c}\text { Planting } \\
\text { Scheme (m) }\end{array}$ & $\begin{array}{l}\text { Planting } \\
\text { Material }\end{array}$ \\
\hline L1 & Sadova & $\begin{array}{l}43^{\circ} 45^{\prime} 05.47^{\prime \prime} \mathrm{N} \\
23^{\circ} 54^{\prime} 56.23^{\prime \prime} \mathrm{E}\end{array}$ & $\begin{array}{l}106 \mathrm{~A} \% \\
(0.47)\end{array}$ & PLEA & $6 \times 4$ & cuttings \\
\hline L2 & Sadova & $\begin{array}{l}43^{\circ} 45^{\prime} 33.59^{\prime \prime} \mathrm{N} \\
23^{\circ} 52^{\prime} 39.86^{\prime \prime} \mathrm{E}\end{array}$ & $\begin{array}{l}88 \mathrm{~B} \% \\
(0.89)\end{array}$ & PLEA & $6 \times 4$ & cuttings \\
\hline L3 & Calafat & $\begin{array}{l}43^{\circ} 57^{\prime} 58.03^{\prime \prime} \mathrm{N} \\
22^{\circ} 52^{\prime} 55.42^{\prime \prime} \mathrm{E}\end{array}$ & $\begin{array}{c}91 \mathrm{~B} \\
(0.96)\end{array}$ & PLEA & $4 \times 4$ & cuttings \\
\hline L4 & Poiana Mare & $\begin{array}{l}43^{\circ} 50^{\prime} 51.35^{\prime \prime} \mathrm{N} \\
23^{\circ} 36^{\prime} 06.75^{\prime \prime} \mathrm{E}\end{array}$ & $\begin{array}{c}22 \mathrm{C} \\
(2.91)\end{array}$ & PLA & $3 \times 2$ & seedlings \\
\hline L5 & Poiana Mare & $\begin{array}{l}43^{\circ} 50^{\prime} 12.70^{\prime \prime} \mathrm{N} \\
23^{\circ} 11^{\prime} 10.63^{\prime \prime} \mathrm{E}\end{array}$ & $\begin{array}{c}43 \mathrm{~A} \\
(1.45)\end{array}$ & PLA & $3 \times 2$ & seedlings \\
\hline L6 & Dăbuleni & $\begin{array}{l}43^{\circ} 45^{\prime} 01.60^{\prime \prime} \mathrm{N} \\
23^{\circ} 57^{\prime} 33.55^{\prime \prime} \mathrm{E}\end{array}$ & $\begin{array}{l}7 \mathrm{~A}, 2 \mathrm{D} \\
(1.81)\end{array}$ & PLEA & $5 \times 4$ & seedlings \\
\hline L7 & Poiana Mare & $\begin{array}{l}43^{\circ} 50^{\prime} 49.75^{\prime \prime} \mathrm{N} \\
23^{\circ} 10^{\prime} 19.30^{\prime \prime} \mathrm{E}\end{array}$ & $\begin{array}{c}31 \mathrm{~F}, 31 \mathrm{~N} \\
(1.61)\end{array}$ & PLA & $3 \times 2$ & seedlings \\
\hline L8 & Dăbuleni & $\begin{array}{l}43^{\circ} 44^{\prime} 49.21^{\prime \prime} \mathrm{N} \\
23^{\circ} 59^{\prime} 33.56^{\prime \prime} \mathrm{E}\end{array}$ & $\begin{array}{l}9 \mathrm{D}, 10 \mathrm{~A} \\
(4.16)\end{array}$ & PLEA & $5 \times 4$ & seedlings \\
\hline
\end{tabular}

In the planting sites L1-L3, the used planting material consisted of large poplar cuttings (PLEA, average length, diameter at the thick end, and weight estimated at approximately $6 \mathrm{~m}, 70 \mathrm{~mm}$, and $5 \mathrm{~kg}$, respectively); in the rest of planting sites, bare-root seedlings of both PLEA ( $2.5 \mathrm{~m}$ in height and $15 \mathrm{~mm}$ in diameter) and PLA (1.5 $\mathrm{m}$ in height and $8 \mathrm{~mm}$ in diameter) species were used for planting. Cuttings and seedlings used as planting material were procured from the plant reproduction facilities located in Zăval (Dolj county) and were transported to the planting sites on distances ranging from 10 to $110 \mathrm{~km}$.

At the field study dates, all the planting sites were prepared in the sense that pits were already configured. In most of the planting sites, the existing stumps were previously removed and the soil was mechanically mobilized before the configuration of the pits. The soils of the planting sites were specific to the area, which is located near the Danube river, being either of alluvial origin or having a high content of sand.

\subsection{Selection of Subjects and Organization of Work}

Selection of the subjects for field monitoring was based on several criteria that covered, mainly, the availability and technical limitations of the monitoring devices, the informed consent of the subjects to participate in the study, and a specific distribution and inclusion of the work elements that were designed to emulate all the tasks specific to manual planting. As the existing Romanian planting rates for poplar seedlings indicate that the teams may be composed of 2 to 5 workers [17], and given the technical limitations of the devices used in this study, a number of two subjects were randomly selected for field monitoring in each study location. Following the selection, one subject was observed in three study locations; the final sample of subjects covered 14 male individuals (Table 2). Before observation, each subject was interviewed to collect data on his basic anthropometric features (Table 2) and to explain to him in detail the scope of the study and the intended use of the data. Based on this data, the body mass index (BMI) of each subject was computed in the office phase of the study. The sample of subjects selected for observation was characterized by an age of $43.3 \pm 11.0$ years, a body weight of $78.1 \pm 9.5 \mathrm{~kg}$, a body height of $1.73 \pm 0.06 \mathrm{~m}$, and a body mass index of $26.8 \pm 2.7$. The selected subjects were experienced in planting operations and they were instructed to carry on their jobs as usual. All the subjects participating in the study expressed their wish to remain anonymous. 
Table 2. Basic anthropometric characteristics of the study group and locations of observation.

\begin{tabular}{ccccccc}
\hline Subject & $\begin{array}{c}\text { Abbreviation in } \\
\text { This Study }\end{array}$ & Age (years) & $\begin{array}{c}\text { Body } \\
\text { Weight (kg) }\end{array}$ & $\begin{array}{c}\text { Body } \\
\text { Height (m) }\end{array}$ & $\begin{array}{c}\text { Body Mass } \\
\text { Index }\end{array}$ & $\begin{array}{c}\text { Location of Field } \\
\text { Observation }\end{array}$ \\
\hline Subject 1 & S1 & 53 & 81 & 1.75 & 26.45 & L1 \\
Subject 2 & S2 & 38 & 78 & 1.65 & 28.65 & L1 \\
Subject 3 & S3 & 27 & 74 & 1.73 & 24.731 & L2 \\
Subject 4 & S4 & 50 & 95 & 1.82 & 28.68 & L2, L4, L5 \\
Subject 5 & S5 & 45 & 87 & 1.85 & 25.42 & L3 \\
Subject 6 & S6 & 20 & 69 & 1.74 & 22.791 & L3 \\
Subject 7 & S7 & 49 & 78 & 1.70 & 26.99 & L4 \\
Subject 8 & S8 & 48 & 80 & 1.70 & 27.68 & L5 \\
Subject 9 & S9 & 51 & 83 & 1.75 & 27.10 & L6 \\
Subject 10 & S10 & 40 & 85 & 1.69 & 29.76 & L6 \\
Subject 11 & S11 & 54 & 75 & 1.70 & 25.95 & L7 \\
Subject 12 & S12 & 52 & 55 & 1.65 & 31.93 & L8 \\
Subject 13 & S13 & 28 & 70 & 1.80 & 21.601 & L8 \\
Subject 14 & S14 & 51 & 83 & 1.75 & 27.10 & \\
\hline
\end{tabular}

${ }^{1}$ Denotes a normal weight according to Body Mass Index.

Typical organization of the work was deduced in the office phase of the study based on the field collected data. In this regard, there were some differences as specific to the two types of planting material used. Cutting planting operations (hereafter $\mathrm{CP}$ ) consisted of several work tasks such as the cutting sharpening, which is typically done to enhance the survival rate and for a better placement into the pit by pushing (Figure 1d), cutting handling and distribution within the planting site, cutting placement into the pit, which involved some pushing of the planting material (Figure 1c), pit filling with soil, gradual soil compaction by a handled tool and the subjects' movement between the pits; these were complemented by technical, personal, meal, and study-caused delays. In the case of seedling planting operations (hereafter SP), the differences consisted of the way used to place the seedlings into the pits as well as the way used to compact the soil. In both cases, the soil was gradually placed and compacted into the pits, but in the case of SP, soil compaction was done using the feet (Figure 1a).

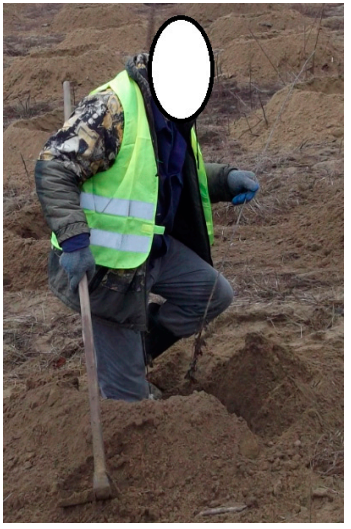

(a)

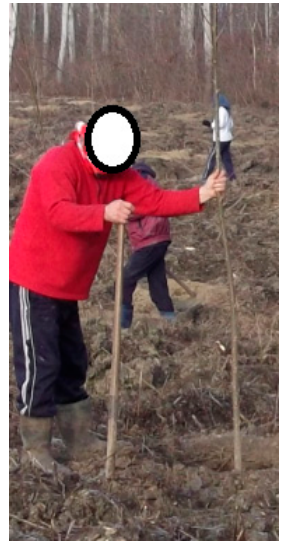

(b)

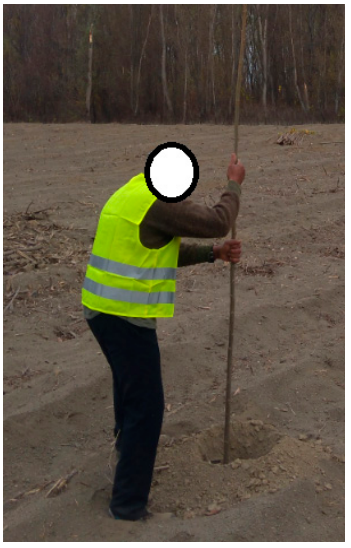

(c)

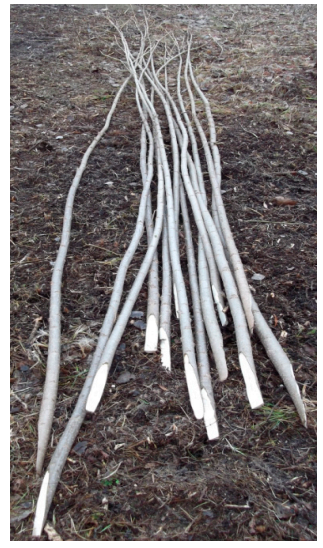

(d)

Figure 1. Examples of typical planting operations and planting material used: (a) Manual planting of PLA seedlings; (b) manual planting of PLEA seedlings; (c) manual planting of PLEA cuttings; (d) sharpened PLEA cuttings.

Other events consisted of moving by foot between nearby planting sites and unloading the planting material from the transportation means. These accounted for low shares and were not typical for all the subjects taken into the study. All the tasks described above and which supposed planting were done manually and, procedurally, the study was designed to cover at least 100 min of operation per day of observation, subject, and study site. This was considered to be sufficient to cover different 
time-windows of the day, several repetitions of all the tasks, and the observation of all the body postures assumed by subjects during their work. In addition, the sites to be planted by the described operations are typically small in area. Once the workers have finished the work on one site, they move to the next one. Nevertheless, to produce more reliable data, and since the operations allowed it, in some sites field data collection was extended to more than $200 \mathrm{~min}$. Given the limited availability of planting sites for the studied operations, it was not possible to implement a balanced approach to get the same number of sites for each condition (planting material and planting scheme used). To accommodate this situation, the approach used in data processing and analysis enabled comparisons for unbalanced designs.

\subsection{Data Collection}

The primary field data was collected by video monitoring of operations. A small-sized $(10 \times 6 \times 2 \mathrm{~cm})$ Schwartz B1080 video camera was mounted on a tripod and set to continuously collect video files of $20 \mathrm{~min}$ in length each; this media file length is the maximum one enabled by the camera and, when reaching it, the camera saves it and automatically starts the next recording session of $20 \mathrm{~min}$. This automatic procedure of recording and saving media files was applied until the work of the subjects had been finished in each planting site taken into the study. Due to a small setting error, in one site the length of consecutively collected video files was set accidentally to $3 \mathrm{~min}$, but this did not affect the approach of the study, since in some sites the last of the collected video files taken into analysis were shorter than $20 \mathrm{~min}$, anyway, because the planting work was finished before reaching the full length of the media file. The camera collected full HD video data $(1920 \times 1080$ pixels $)$ using a field of view of $90^{\circ}$ oriented towards the two subjects monitored on each site. It was equipped with an internal accumulator of $4000 \mathrm{mAh}$ that enables a video recording duration of up to $8 \mathrm{~h}$, and the data was stored on a memory card of $32 \mathrm{~GB}$. The camera was successively moved within each planting site as the operations progressed and it was placed each time at up to ca. $15 \mathrm{~m}$ from the observed subjects, enabling a clear vision on the subjects' postures. However, in most of the cases, the distance between the camera and the subjects was much less, close to ca. $5 \mathrm{~m}$. As such, the approach provided the extraction of high-quality pictures, which were similar to those shown in Figure 1. On each site, after the completion of daily data collection, video files were transferred on a computer and saved in folders named by the date and site of data collection.

\subsection{Data Processing and Statistical Analysis}

A first step of data processing consisted of a sampling procedure that aimed to extract representative images for postural analysis. Given the previous experience with sampling and handling such data [22], and under the assumption that some of the data extracted from the video files will not be suitable for analysis, the targeted sample was designed to cover a number of exactly 100 randomly extracted images per $20 \mathrm{~min}$ of video recording (approximately $8 \%$ of the video sampled data). For this reason, pseudo-random numbers [23] were generated in Microsoft Excel (Microsoft Excel 2013, Microsoft, Redmond, WA, USA) in an interval that covered the length of each video file measured in seconds. Irrespective of the planting site, for those video files that had $20 \mathrm{~min}$ in length, 100 random numbers were generated, while for shorter files the numbers were generated proportionally with their length. This procedure was applied to all the video files collected in each plot as shown in Table 3. The extracted numbers were saved as lists for each video file taken into analysis, then each video file was broken into frames extracted at a rate of $1 \mathrm{~Hz}$. In a following step, based on the list of random numbers, the corresponding frames were selected and organized in folders by considering the video file, subject, and study site to which they belonged. Postural analysis was implemented by using the Ovako Working posture Analysis System (OWAS) postural analysis method as described in [24], and it aimed also to document the tasks to which the analyzed frames belonged. The concept used in the implementation of the postural analysis method was based on the typical characteristics of a frequency study carried at random intervals as defined in [25]. To do so, and where the case allowed, each frame taken into study was analyzed in conjunction with the video file to which it belonged, to be able to accurately describe 
the work task it depicted. This supposed a detailed analysis of the video file some seconds before and after the occurrence of a given frame in it, by playing the video file and seeing the events depicted by them. For instance, if a subject was identified in the video file in a still state following a previous work task that supposed body movement, it was assumed that the frame in question belonged to a rest pause. Similarly, if a worker has been seen in a media file to handle either a cutting or a seedling by putting it into a pit, then it was assumed that the frame occurring in that part of the movie belonged to the effective planting. This approach was used due to the specific limitations of the OWAS method, as described, for instance, in [26].

Table 3. Description of the field sampled and office processed data.

\begin{tabular}{ccccccc}
\hline $\begin{array}{c}\text { Subject } \\
\text { and } \\
\text { Location }\end{array}$ & $\begin{array}{c}\text { Type of } \\
\text { Planting } \\
\text { Operation }\end{array}$ & $\begin{array}{c}\text { Number } \\
\text { of Video } \\
\text { Files }\end{array}$ & $\begin{array}{c}\text { Length of } \\
\text { Video Files (s) }\end{array}$ & $\begin{array}{c}\text { Number of } \\
\text { Analyzed } \\
\text { Frames }\end{array}$ & $\begin{array}{c}\text { Number of Valid } \\
\text { and Reorganized } \\
\text { Frames }\end{array}$ & $\begin{array}{c}\text { Share of Valid and } \\
\text { Reorganized Frames in } \\
\text { the Collected Data (\%) }\end{array}$ \\
\hline S1 $\times$ L1 & CP & 6 & 7200 & 600 & $419\left(417^{3}\right)$ & $5.82\left(5.79^{4}\right)$ \\
S2 $\times$ L1 & CP & 6 & 7200 & 600 & $410\left(406^{3}\right)$ & $5.69\left(5.64^{4}\right)$ \\
S3 $\times$ L2 & CP & 12 & 14,400 & 1200 & $787\left(781^{3}\right)$ & $5.47\left(5.42^{4}\right)$ \\
S4 $\times$ L2 & CP & 12 & 14,400 & 1200 & $833\left(832^{3}\right)$ & $5.78\left(5.78^{4}\right)$ \\
S5 $\times$ L3 & CP & 9 & 10,800 & 900 & $659\left(653^{3}\right)$ & $6.10\left(6.05^{4}\right)$ \\
S6 $\times$ L3 & CP & 9 & 10,800 & 900 & $707\left(707^{3}\right)$ & $6.55\left(6.55^{4}\right)$ \\
S7 $\times$ L4 & SP & 20 & $23,400^{1}$ & 1772 & $1522\left(1510^{3}\right)$ & $6.50\left(6.45^{4}\right)$ \\
S4 $\times$ L4 & SP & 20 & $23,400^{1}$ & 1772 & $1358\left(1349^{3}\right)$ & $5.80\left(5.76^{4}\right)$ \\
S8 $\times$ L5 & SP & 81 & $14,580^{2}$ & 1215 & $864\left(818^{3}\right)$ & $5.93\left(5.61^{4}\right)$ \\
S4 $\times$ L5 & SP & 81 & $14,580^{2}$ & 1215 & $820\left(679^{3}\right)$ & $5.62\left(4.66^{4}\right)$ \\
S9 $\times$ L6 & SP & 12 & $13,700^{1}$ & 1140 & $732\left(722^{3}\right)$ & $5.34\left(5.27^{4}\right)$ \\
S10 $\times$ L6 & SP & 12 & $13,700^{1}$ & 1140 & $738\left(729^{3}\right)$ & $5.39\left(5.322^{4}\right)$ \\
S11 $\times$ L7 & SP & 14 & 16,800 & 1400 & $967\left(967^{3}\right)$ & $5.76\left(5.76^{4}\right)$ \\
S12 $\times$ L7 & SP & 14 & 16,800 & 1400 & $898\left(880^{3}\right)$ & $5.35\left(5.24^{4}\right)$ \\
S13 $\times$ L8 & SP & 17 & $19,860^{1}$ & 1650 & $1373\left(1197^{3}\right)$ & $6.91\left(6.03^{4}\right)$ \\
S14 $\times$ L8 & SP & 17 & $19,860^{1}$ & 1650 & $1377\left(1211^{3}\right)$ & $6.93\left(6.10^{4}\right)$ \\
\hline
\end{tabular}

${ }^{1}$ One video file was shorter than $20 \mathrm{~min} .{ }^{2}$ Video files were collected at $3 \mathrm{~min}$ in length each. ${ }^{3}$ Number of frames used in the final analysis after the reorganization of work tasks. ${ }^{4}$ Share of frames used in the final analysis in the total number of frames extracted at $1 \mathrm{~Hz}$ rate from the video files.

The data was analyzed by four researchers who had an extensive experience in handling the method and in the procedures used in data processing and analysis. Frames that were not suitable for analysis were disregarded. The exclusion process considered those frames that, for some reason, failed to clearly show all the body components taken into analysis due to the position of the worker in the field of view, those in which other persons obstructed the view on the worker under study by crossing the camera's field of view, as well as those frames which failed to capture useful data due to the need to move forward the tripod and the camera. The rest were kept as valid and were used in the postural analysis. The analyzed data, consisting of the code attributed to each body part according to the OWAS method, as well as a descriptive code to indicate the tasks observed, was included into Microsoft Excel sheets for each location and subject taken into study. Table 3 shows the basic statistics of the data used in this study. A total number of 5400 (CP) and 14,354 (SP) frames were extracted, covering and describing an observation time of approximately 18 and $49 \mathrm{~h}$ for $\mathrm{CP}$ and SP, respectively. Of these, 3815 (71\%) were kept as valid for CP, and 10,649 (74\%) were kept as valid for SP.

While all the work tasks and delays were monitored and separated based on the video data, some conceptual readjustments were necessary to target only the tasks specific and common to the two types of planting operations (CP and SP, respectively), as well as to enable the comparability between them in terms of postures assumed during the work. For that reason, the concept used in data analysis covered only those tasks that referred strictly to the studied operations. As such, frames that described meal, study-caused, and technical delays were excluded, and only those describing personal delays (hereafter Rest) were retained for analysis because these corresponded to resting pauses taken by the subjects in the planting sites. On the other hand, delays caused by meal taking were specific only to a part of subjects and study sites, therefore keeping them in the analysis would 
have affected the comparability of data. An additional step, which was undertaken to enhance the comparability, consisted of task regrouping and recoding to describe only four categories of tasks that were observed to be common to both types of operations: Moving (hereafter Move), which grouped all the reorganized frames (Table 3) in which the subjects were identified as moving between planting pits, moving within the planting site to bring planting material and so on, distributing (hereafter Distribute), which grouped the reorganized frames depicting actions of movement and placement of planting material near the pits, planting (hereafter Plant), that supposed the grouping of all the reorganized frames describing actions such as cutting sharpening, placement of cuttings or seedlings into the pits, filling the pits with soil, and compacting the soil, etc., and Rest, as described before.

Data analysis consisted of implementing the common procedures to see if the studied operations are sustainable from the point of view of postural condition. To do so, data was aggregated and analyzed at three levels: Tasks, subjects, and operation type. The distributions of the reorganized frames per tasks was analyzed by considering the last two levels, by the means of a relative frequency study which was implemented first at subject (site) level, then at the operation type (CP, SP) level. This approach allowed for a raw comparison in terms of task shares between the subjects (sites) and types of operations, respectively. Postural analysis aimed to estimate the postural risk index (hereafter PRI), as described by Zanuttini et al. [27] and used in this kind of research in forest operations [22,28-31], at task, subject, and operation type level. To do so, the input data was aggregated into datasets describing these three levels. From this point of view, the codes attributed when using the OWAS method consist of four digits $[16,26]$ that can be further documented by a description of the task [16] to which a given instance (i.e., a frame extracted from a video file, a field observation by visual means) belongs to. The codes describing given instances by the posture of the back (4 postures), arms (3 postures), legs ( 7 postures), and force exertion ( 3 categories) are leading to a number of 252 possible combinations [26,32]. Of these, 72 are considered to be non-deviant from the regular posture of the body and are included in action category 1 (hereafter AC1) that does not require intervention for improvement, 53 are included in action category 2 (hereafter $\mathrm{AC} 2$ ), which assumes some redesign in the near future, 55 are included in action category 3 (hereafter AC3), which assumes the necessity of intervention as soon as possible, and the remaining 72 are included in action category 4 (hereafter AC4), which supposes immediate intervention for improvement. The postural risk index is calculated based on the relative frequency of observations falling into the four action categories, and it may take values in the range of 100-400 [27]. Based on the above, the postural risk index (PRI) stands for a good metric to check if the data sampled from a population (i.e., a subject working in a given site or an operation type) describes either a sustainable state from an postural point of view or it indicates the need for improvement. As such, values close to 100 characterize a good state from postural point of view, while values close to 400 reflect an urgent need for improvement [27]. While PRIs were calculated at task, subject, and operation level, and they gave the opportunity to visually compare the data, a third step consisted of a statistical comparison between the two operation types (CP and SP) at task and global level, respectively. The comparison was made by the means of Pearson's $\chi^{2}$ statistic test due to the type of the data used and its distribution, which provided an unbalanced design. The input data used in comparison was the relative frequency of the reorganized frames per action categories, and the assumed confidence threshold was set at $\alpha=0.05$. Based on the obtained results, the last step consisted of comparing the data generated by this study with the data coming from similar studies. Acknowledging the fact that the method could have been implemented in many industries, for this last step, however, only studies coming from forest and wood processing operations were selected for comparison. As such, the comparison was made based on the postural risk index as a common metric used to describe the need for intervention, and the comparisons were included in the discussion section. 


\section{Results}

\subsection{Task Share per Subjects and Types of Operations}

Following data reorganization, the share of the remaining frames used to characterize the planting tasks (Move, Distribute, Plant, and Rest) was close to $100 \%$ in most of the cases compared to the set of valid frames.

The exception was that of S13 $\times$ L8 and S14 $\times$ L8, where the shares of the remaining frames were of approximately $87 \%$. This situation was the effect of meal pauses as well as of a more pronounced presence of delays caused by the study in the last two cases. Even so, the share of the remaining frames, compared to the original set extracted at a rate of $1 \mathrm{~Hz}$, was the greatest, accounting for more than $6 \%$ (Table 3). Figure 2 shows the distribution of frames per tasks at subject and operation type level. As it can be observed, there was a variation among the subjects and operation types, but planting (Plant) accounted for the greatest share in the analyzed samples. It represented approximately $60 \%$ in the case of $\mathrm{CP}$ (ranging from 53 to $70 \%$, Figure 2a) and approximately $67 \%$ in the case of SP (ranging from 55 to $89 \%$, Figure $2 b$ ). Differences among the subjects were obvious in both cases (CP and SP) and they were the effect of different degrees of involvement in specific tasks and in particular to those events characterizing the resting pauses (Rest). Distribution tasks (Distribute) accounted for a greater share in the case of CP, and this could be related to the size of the planting material, which required more movements to deliver it to the planting pits. Apparently, there were no correlations between the planting scheme and the share of the movement and distribution tasks. Nevertheless, Move and Distribute accounted for relatively similar shares for most of the subjects working in the same SP site (Figure 2).

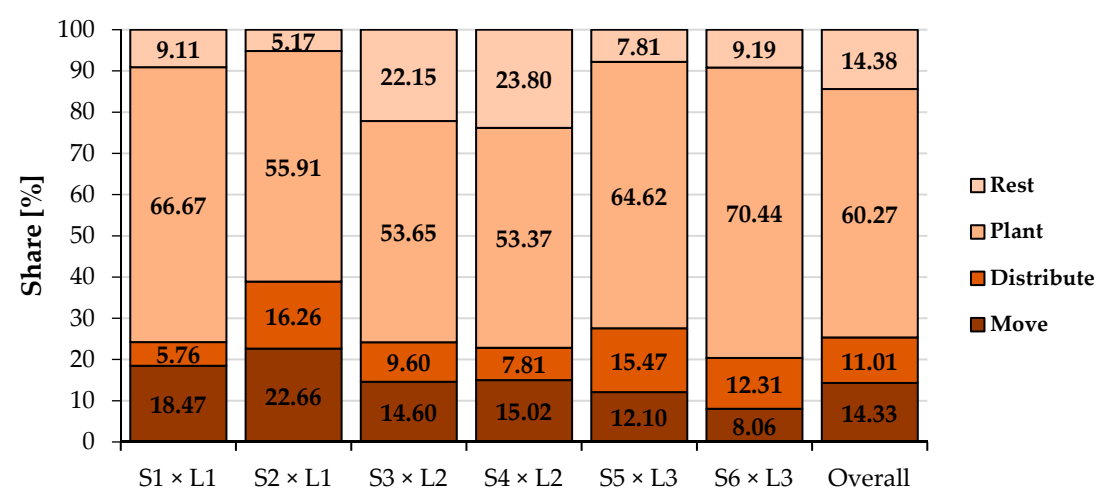

(a)

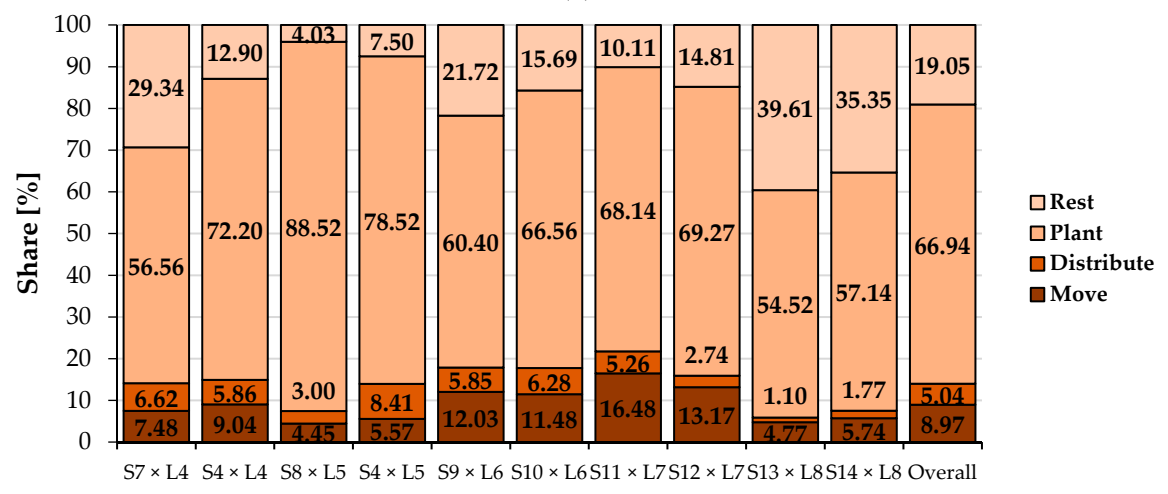

(b)

Figure 2. Share of the reorganized frames on tasks at the subject and operation type level: (a) Cutting planting operations (CP), (b) Seedling planting operations (SP). 


\subsection{Postural Assessment}

\subsubsection{Cutting Planting}

In the case of $\mathrm{CP}$, postural analysis by the means of OWAS method revealed a high inter-task and inter-subject variability of data categorized on action categories, as shown in Figure 3.

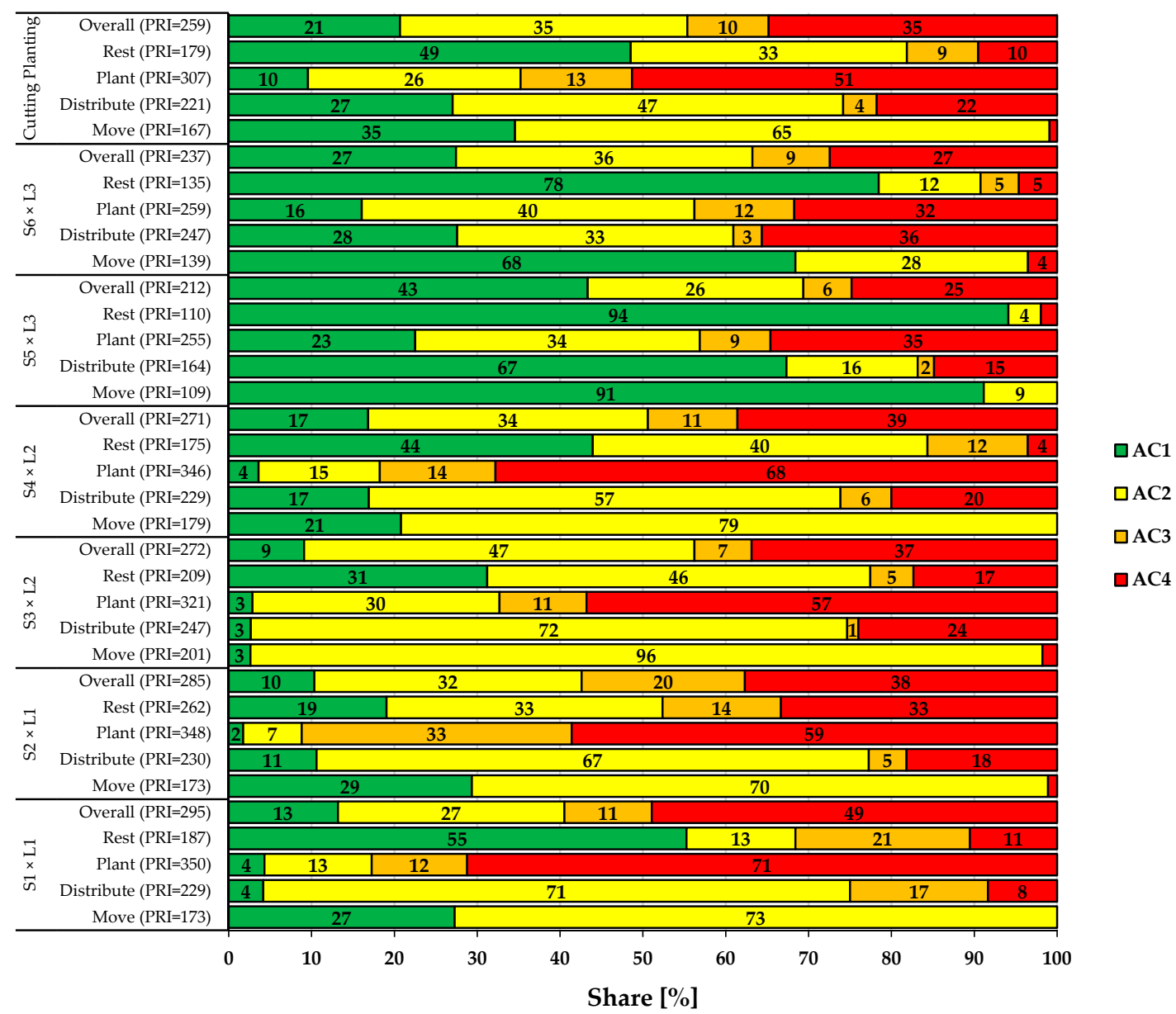

Figure 3. Data distribution on action categories (AC) and the estimated postural risk indexes (PRIs) at task, subject, and operation level for CP operations.

The frames characterizing the Move task were categorized, predominantly in AC1 and AC2. As such, the PRI of this task was evaluated to range, at the subject level, between 109 and 201, averaging 167 at the operation type level. Next in line were the Rest events, whose PRIs ranged from 110 to 262, averaging 179 at the operation level. Distribute task was characterized by values of PRI in between 164 and 247, averaging 221 at the operation level, while the most problematic task was that of planting (Plant), which accounted for PRI values in between 255 and 350, averaging 307 at the operation level. At the subject level, postural risk indexes varied between 212 and 295, while the overall PRI for CP was estimated at 259 .

\subsubsection{Seedling Planting}

The situation on postural analysis as specific to SP operations is given in Figure 4. In this case, Rest events were less problematic as the PRIs were estimated at values in range of 107-189, averaging a value of 148 at the SP operation level. 


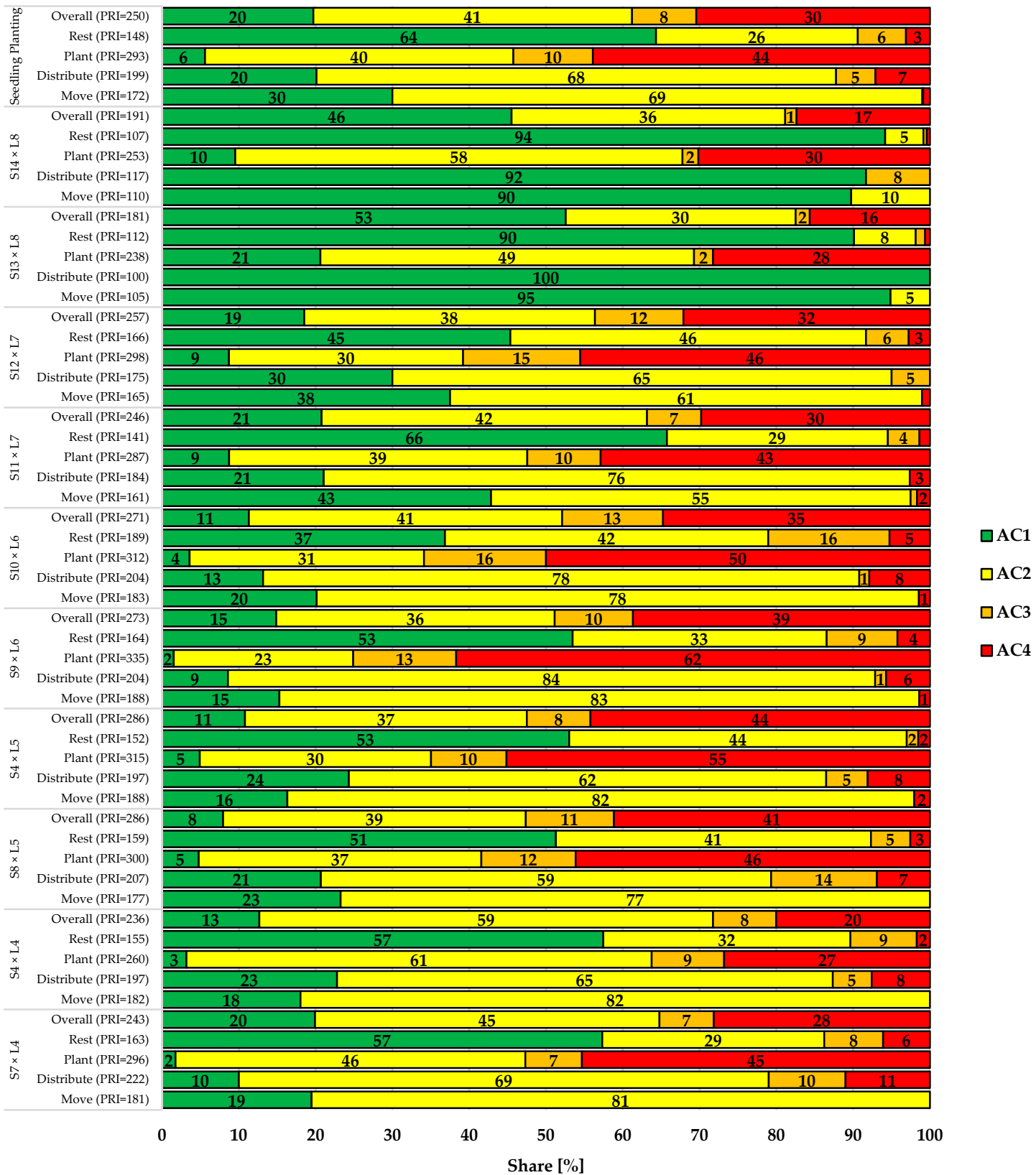

Figure 4. Data distribution on action categories (AC) and the estimated postural risk indexes (PRIs) at task, subject, and operation level for SP operations.

Next in line were the Move, Distribute, and Plant tasks, which were characterized by PRIs in range of 105-188, 100-222, and 238-355, respectively. At the subject level, PRIs varied in between 181 and 286. The overall PRI, calculated for the SP operation, was of 250, but it also varied at task level between 148 (Rest) and 293 (Plant). Therefore, similar to the CP operation, the most problematic task in the case of SP operations was the Plant task.

The results shown in Figures 3 and 4 were related, to some extent, with the distribution of the analyzed frames per tasks (Figure 2). For instance, S13 and S14, which were observed in L8 in the case of SP, were found to have the greatest share of Rest events (40 and 35\%, respectively) in the task breakdown. For these two subjects, the PRIs were found to be the lowest (181 and 191, respectively). At the opposite side were the subjects S4 and S8, which were observed in L5 and for which were identified the lowest shares of Rest events in the task breakdown (Figure 2). Accordingly, for these two 
subjects, the PRIs were the greatest in the case of SP (286). As such, the way in which the work tasks are approached may affect the outcomes in terms of postural risks.

\subsection{Comparison between Operations}

Given the inter-subject variability, a comparison at this level on tasks was not feasible due to the high amount of data to be processed, analyzed, and reported. In turn, an analysis at the global level as well as an analysis at the task level, by considering all the data specific to an operation type, seemed to be more approachable and applicable since the aim of the study was to see if there are differences between the two types of operations and to compare the data with that coming from other studies. As such, the approach was to integrate the variability coming from inter-subject variation. Table 4 shows the results of the comparison tests carried out at the task and operation type level.

Table 4. Results of comparison tests between CP and SP at the task and operation type level.

\begin{tabular}{ccccccc}
\hline \multirow{2}{*}{$\begin{array}{c}\text { Task Name and Tests } \\
\text { Results }\end{array}$} & \multirow{2}{*}{$\begin{array}{c}\text { Operation } \\
\text { Type }\end{array}$} & AC1 & AC2 & AC3 & AC4 & Postural \\
\cline { 3 - 5 } Risk Index \\
\hline Move & CP & 34.56 & 64.52 & 0.00 & 0.92 & 167.28 \\
$\chi^{2}=0.582, p=0.901$ & SP & 30.01 & 68.99 & 0.11 & 0.89 & 171.87 \\
Distribute & CP & 27.03 & 47.13 & 4.07 & 21.77 & 220.57 \\
$\chi^{2}=12.260, p=0.007^{1}$ & SP & 20.12 & 67.65 & 5.13 & 7.10 & 199.21 \\
Plant & CP & 9.57 & 25.66 & 13.46 & 51.31 & 306.51 \\
$\chi^{2}=5.226, p=0.156$ & SP & 5.60 & 40.16 & 10.33 & 43.90 & 292.55 \\
Rest & CP & 48.53 & 33.33 & 8.61 & 9.52 & 179.12 \\
$\chi^{2}=6.641, p=0.084$ & SP & 64.32 & 26.29 & 6.26 & 3.13 & 148.20 \\
Overall & CP & 20.68 & 34.69 & 9.80 & 34.83 & 258.77 \\
$\chi^{2}=1.039, p=0.792$ & SP & 19.71 & 41.49 & 8.38 & 30.42 & 249.51 \\
\hline
\end{tabular}

${ }^{1}$ Denotes significant differences between the relative frequencies per action categories among the two tested types of operations assuming a confidence threshold of $\alpha=0.05$.

Before comparing the data, it is worth mentioning that the PRIs shown in Table 4 were calculated based on the frequencies (number) of the analyzed frames falling in a given action category per task and operation types. By the way of calculation, this metric does not support mean or median values, since it is based on a formula applied to the frequencies of frames. For instance, the PRI of 167.28 as specific to the Move task in $\mathrm{CP}$ was calculated based on the number of frames per action categories coming from all the subjects surveyed in $\mathrm{CP}$ operations.

As shown in Table 4, excepting the Distribute task, for which the test identified significant statistical differences, all the tasks were similar from the point of view of relative frame frequencies per action categories, as specific to the two types of operations. For the Rest events, the specific distribution on action categories failed closely $(p=0.08, \alpha=0.05, p>\alpha)$ to indicate significant differences between the two operation types. Compared to the Distribute task, where the PRIs were close as values, in the case of Rest events, the PRIs were rather different, indicating that the outcome for SP has no serious problems, while the outcome for $\mathrm{CP}$ may have problems related to work postures assumed by the workers. While the postures assumed by the subjects in these events (Rest) are not constrained by the specific job tasks, the results indicate that further research is needed to be able to compare and differentiate more clearly between the inputs and outcomes of specific data sets analyzed by using the OWAS method.

In general, the PRIs calculated for the Move events were close to the value of 200, a value which can be interpreted in the way that some improvement may be required in the near future. The same may be applied to the Rest events, but here the improvements may rest in the free will of the subject to implement them, and they may be less related to the organization and technology of work. Similar figures (PRI close to 200) were found for the Distribute tasks, but the greatest problem lies in the results found for Plant tasks which were close to 300, and which indicate that immediate actions need to be undertaken for improvement. In addition, the Plant tasks were dominant in the analyzed data sets, 
being also, in general, dominant in planting operations. The PRIs found at the operation type level indicate that measures for improvement are needed rather urgently. Even if the differences between the two types of operations were not statistically significant, it is worth mentioning that $\mathrm{CP}$ tasks received, in most of the cases, higher PRIs compared to SP. This was more evident in the case of Plant tasks (difference of approximately 6 points), indicating also a similar problem related to data comparability, which should be researched in the future.

\section{Discussion}

The postural risk associated with the studied manual planting operations was found to be high, irrespective of the analyzed option (CP and SP, respectively). At the task level, the effective planting (Plant) was found to generate the worst postural situation because the PRIs were estimated to be close to 300 . Unfortunately, by keeping the current situation, there is little room for improvement, as the effective planting stands for the main task specific to the studied planting operations and it accounts for the greatest share in the analyzed data. Even if not presented in the results section, the dominant body postures specific to AC4, that generated the current situation, were 4141 and 4151, respectively (where the first digit -4 stands for the back bent and twisted or bent forward and sideways, 1 -both arms below the shoulder level, 4 and 5-standing or squatting with both or one knee bent, respectively, while the last digit stands for force exertion less than $10 \mathrm{~kg}$ ). These were specific to the Plant task and they accounted for 1147 and 2949 observations for CP and SP, respectively, representing 30\% and 28\% of the analyzed data sets. Therefore, the main problems were related rather to the back (code 4) and leg (codes 4 and 5) postures, indicating that the back was either bent and twisted or bent forward and sideways. Accordingly, the legs were found to be with one (code 4) or both (code 5) knees bent in a standing or squatting posture. These postures of the back and legs are among the most deviant according to the OWAS method, and they were imposed by the actions and motions needed to place the cuttings and seedlings into the pits as well as those needed to fill the pits and to compact the soil in them. Elucidating for these tasks are also the examples given in Figure 1.

Worth mentioning that in the task breakdown, the Rest events were found to present shares of 5-24 and 4-40\% for CP and SP, respectively. While these events were kept into analysis because they were related to the on-site work, and were intercalated in the typical work sequence, it is highly questionable if they could be eliminated or reduced in the general operational conditions. If so, then based on the results and task distribution presented by this study, the postural risk situation would become even worse, while the productivity will not be significantly enhanced. For instance, the total operated area (results not presented herein) in CP sites was of $0.55 \mathrm{ha}$, while in the case of SP it was of 1.46 ha. Nevertheless, these areas were operated by cohorts containing many more workers than those taken into study. Taking into consideration that the observation time was of 18 and $49 \mathrm{~h}$, respectively, the global productivity could be estimated at approximately 0.03 ha per hour for both $\mathrm{CP}$ and SP, which was very low for the observed conditions, and it would become even lower if higher rest pauses will be taken. This situation indicates the limitations of manual work as being one of the current problems in forest operations.

Another approach which is seen as a potential ergonomic improvement is that of job rotation in the sense that work stations or tasks could be more wisely distributed between workers with the aim to reduce the postural risk. Spinelli et al. [31] have proposed such an approach for wood debarking jobs as a measure to balance the effect of difficult work postures. Nevertheless, in the case of manual planting this approach is less useful due to the task sequence and share in the typical work, in which the effective planting will dominate irrespective of how the tasks will be redistributed among workers. In addition, the job itself is different compared to assembly lines or jobs in similar industries in which, anyway, recent work has revealed that job rotation could be less effective [33].

Probably, one of the important factors that could have affected the results from an anthropometric point of view was the subjects' body height, which varied between 165 and $185 \mathrm{~cm}$. For comparison, these two body heights were found in the case of $\mathrm{CP}$ for $\mathrm{S} 2 \times \mathrm{L} 1$ and S5 $\times \mathrm{L} 3$, respectively, cases in which 
the Rest events also accounted for low shares (approximately 5 and $8 \%$, respectively). As such, the PRIs for the Plant tasks were found to be of $348(165 \mathrm{~cm})$ and $255(185 \mathrm{~cm})$, respectively, indicating that lower body heights could be associated with higher postural risks. However, one may just speculate that part of these outcomes may be the results of the places at which some of the subjects have chosen to grip the cuttings with their arms when they worked to introduce them into the pits, as the arms postures coded by 2 (one arm above the shoulder level) and 3 (both arms above the shoulder level) accounted for less than 200 events in the case of CP.

A comparison with other studies helps in understanding and categorizing these kinds of operations by considering the postural risk. Studies by Marogel et al. [22] and Cheţa et al. [29] have addressed the problem in cultivated forests located in the same region for manual cultivation and motor-manual tree felling and processing operations, respectively. The study by Marogel et al. [22] estimated a global PRI at 178 based on a cohort containing 14 subjects but, at the subject level, the PRI varied between 151 and 212. The operations surveyed by them were done manually by hoes, and the share of observations falling in AC4 was much lower (approximately 5\%) compared to that from this study $(30-35 \%)$. The study of Cheţa et al. [29], on the other hand, estimated the PRI of motor-manual tree felling and processing at 275 , which was close to other similar forest operations as described by Calvo [32]. Therefore, it seems that operations that involve more leg movement such as those described by Marogel et al. [22], Borz et al. [28], as well as those that show a wider and more diverse succession of tasks [27] present lower postural risks, which are characterized by PRIs of up to 200. In comparison, wood processing operations were characterized by different classes of PRIs which range from non-threatening situations such as those specific to wood debarking [31], for which PRIs were found to be of up to 150, to those requiring postural improvement, such as in the case of firewood processing [30] and sawmilling [34], for which the PRIs were identified to be up to or even higher than 200. From this analysis, it seems that manual planting operations surveyed in this study hold an intermediary position, as they indicated PRIs of 250-259. Nevertheless, this situation requires immediate intervention for improvement, which is also supported by the statistics developed for the effective planting tasks (Plant) and by the assumption that, in other cases, the Rest events could have a lower share in the operations. Additionally, it is worth mentioning that, even if it seems to be unreasonable to find PRIs higher than 100 for Rest events, as shown by this study, and also found by other studies [27], this situation is real in operations. In addition, comparison of jobs by considering the estimates of PRI has its own limitations because is quite difficult to infer the typical postures of body parts from which the PRIs are obtained. A better task or job comparison would have been enhanced under the assumption that all the reported studies indicate the shares per action categories, which would enable the comparison by nonparametric tests. Nevertheless, this approach doesn't say much about the type and frequency of body part postures, which makes the analysis basis, and could be important in the work redesign effort.

Given the situation identified by this study, a good approach for improvement will be that of completely mechanizing the operations. This approach could be feasible, since some studies have shown that performance of mechanized planting reaches acceptable limits, and seedling planting machines could handle plants of different sizes [6]. Nevertheless, for the time being, the complete mechanization of poplar planting operations could be difficult since, at least for the cutting planting, special machines need to be developed. However, machines able to handle both soil preparation and planting using the described planting material and its size need to be developed in a short time given the limited availability of work force, low productivity, poor postural conditions of manual planting operations, and the spatial characteristics of such operations (i.e., sites having areas of up to 3 hectares, widely dispersed in the territory).

In regards to the method used in this study, one could appreciate the fact that even though it is resource-intensive in data processing and analysis, a fact that has been found by the authors of this study by their experience with other studies [22,29], it still provides the option of carrying on the studies by using affordable technology. While there are many other observational methods [15], 
the use of OWAS has gained attention, in particular in forest operations [see the reference list], due to its ability to evaluate the whole body and the possibility to provide comparable results. However, the method produces categorical data as outputs, which is difficult to address by the estimation of some advanced postural variability and diversity metrics that could work well for data measured on continuous scales [35]. Such approaches may be used to characterize given jobs and to better connect their postural condition to the development of MSD. They worth exploring further to see the extent to which they could be used to account for categorical data variability. Last, but not least, there is an increasing body of studies that bring evidence on less association between biomechanical postures and the development of MSDs [36]. While the topic is still debated, further exploration is required to see if the postures adopted during the work are the sole factor causing MSDs. This is important especially in forest operations where the workers are exposed, in addition to job-related risks, to other harmful environmental and technology-related factors [14,37].

\section{Conclusions}

The main conclusion of this study is that the manual poplar planting operations need interventions to correct the postures assumed during the work. As the results of this study have shown that the effective planting accounts for the greatest share in the observed operations, the intervention should be oriented towards finding feasible ways to improve the working postures in this kind of task because it also returned the most unfavorable situation from a postural point of view. While this study does not explicitly address the mechanization or training issues, it is likely that by following these two paths, improvements will be brought in the ergonomics of poplar planting operations.

Author Contributions: Conceptualization, S.A.B.; data curation, T.M.-P., M.V.M., and S.A.B.; formal analysis, T.M.-P., M.V.M., and S.A.B.; investigation, T.M.-P.; methodology, S.A.B.; project administration, S.A.B.; resources, T.M.-P., M.V.M., and S.A.B.; software, M.V.M.; supervision, S.A.B.; validation, T.M.-P., M.V.M., and S.A.B.; visualization, M.V.M. and S.A.B.; writing-original draft, S.A.B.; writing-review \& editing, S.A.B. All authors have read and agreed to the published version of the manuscript.

Funding: This research received no external funding.

Acknowledgments: The authors acknowledge the technical and logistic support of Department of Forest Engineering, Forest Management Planning and Terrestrial Measurements, Faculty of Silviculture and Forest Engineering, Transilvania University of Brasov. The authors would like to thank the local managers of National Forest Administration-RNP Romsilva-for agreeing to carry on this study in the forests managed by them, to Eng. Marius Cheţa and Eng. Diana Chiriloiu for their help in data handling and analysis, and to the subjects who agreed to participate in the study, for their support. This work is part of a PhD thesis developed under the supervision of Doctoral School of the Transilvania University of Braşov. The authors acknowledge the support of the aforementioned organization.

Conflicts of Interest: The authors declare no conflict of interest.

\section{References}

1. Dickmann, D.I.; Kuzovkina, J. Poplars and willows of the world, with emphasis on silviculturally important species. In Trees for Society and the Environment; Isebrands, J.G., Richardson, J., Eds.; The Food and Agriculture Organization of the United Nations and CABI: Rome, Italy, 2014; Volume 2, pp. 8-12.

2. FAO. Improving Lives with Poplar and Willows. Synthesis of Country Progress Reports-Activities Related to Poplar and Willow Cultivation and Utilization-2008 Through 2011. In 24th Session of the International Poplar Commission, Dehradun, India, 29 October-2 November 2012; Working Paper Ipc/12; 93p; Forest Assessment, Management and Conservation Division, FAO: Rome, Italy, 2012; 104p. Available online: http://www.fao.org/forestry/ipc2012/en/ (accessed on 24 February 2019).

3. Drew, A.P.; Zsuffa, L.; Mitchell, C.P. Terminology relating to woody plant biomass and its production. Biomass 1987, 12, 79-82. [CrossRef]

4. Florescu, I.; Nicolescu, N.V. Silviculture; Lux Libris Publishing House: Brasov, Romania, 1996.

5. Abrudan, I.V. Impăduriri; Editura Universității Transilvania din Brașov: Brasov, Romania, 2006.

6. Niuwenhuis, M.; Egan, D. An evaluation and comparison of mechanised and manual tree planting on afforestation and reforestation sites in Ireland. Int. J. For. Eng. 2002, 3, 11-23. [CrossRef] 
7. Laine, T.; Saksa, T. Mechanized tree planting in Sweden and Finland: Current state and key factors for future growth. Forests 2018, 9, 370.

8. Boja, N.; Boja, F.; Teușdea, A.; Vidrean, D.; Marcu, M.V.; Iordache, E.; Duţă, C.I.; Borz, S.A. Resource allocation, pit quality, and early survival of seedlings following two motor-manual pit-drilling options. Forests 2018, 9, 665. [CrossRef]

9. Marogel-Popa, T.; Marcu, M.V.; Cheța, M.; Nuţă, I.S.; Borz, S.A. Dificultatea muncii în operații de plantare a puieților și a sadelor de plop: Analiza ritmului cardiac. Rev. Pădur. 2020, 135, 43-62. (In Romanian)

10. Moskalik, T.; Borz, S.A.; Dvořák, J.; Ferencik, M.; Glushkov, S.; Muiste, P.; Lazdinš, A.; Styranivsky, O. Timber harvesting methods in Eastern European countries: A review. Croat. J. For. Eng. 2017, 38, 231-241.

11. Åstrand, P.O.; Rodahl, K. Textbook of Work Physiology_Physiological Bases of Exercise, 3rd ed.; Human Kinetics: Champaign, IL, USA, 1986.

12. Marchi, E.; Chung, W.; Visser, R.; Abbas, D.; Nordfjell, T.; Mederski, P.S.; McEwan, A.; Brink, M.; Laschi, A. Sustainable forest operations (SFO): A new paradigm in a changing world and climate. Sci. Total Environ. 2018, 634, 1385-1397. [CrossRef]

13. Heinimann, H.R. Forest operations engineering and management-The ways behind and ahead of a scientific discipline. Croat. J. For. Eng. 2007, 28, 107-121.

14. Potočnik, I.; Poje, A. Forestry ergonomics and occupational safety in high ranking scientific journals from 2005-2016. Croat. J. For. Eng. 2017, 38, 291-310.

15. David, G.C. Ergonomic methods for assessing exposure to risk of factors for work-related musculoskeletal disorders. Occup. Med. C. 2005, 55, 190-199. [CrossRef]

16. Helander, M. A Guide to Human Factors and Ergonomics, 2nd ed.; CRC Press: Boca Raton, FL, USA, 2006; pp. 224-255.

17. Lupuşoru, V.; Diaconu, M.; Diaconu, S.; Ionele, A. Norme de Timp şi Producţie Unificate Pentru Lucrări din Silvicultură; S.C. ROF S.A. Suceava: Suceava, Romania, 1997.

18. Hanson, J.A.; Jones, P.P. Heart rate and small postural changes in man. Ergonomics 1970, 13, 483-487. [CrossRef] [PubMed]

19. Jones, A.Y.M.; Kam, C.; Lai, K.W.; Lee, H.Y.; Chow, H.T.; Lau, S.F.; Wong, L.M.; He, J. Changes in heart rate and R-wave amplitude with posture. Chin. J. Physiol. 2003, 46, 63-69. [PubMed]

20. Šipinková, I.; Hahn, G.; Meyer, M.; Tadlánek, M.; Hájek, J. Effect of respiration and posture on heart rate variability. Physiol. Res. 1997, 46, 173-179.

21. Şofletea, N.; Curtu, L. Dendrologie, 2nd ed.; Pentru Viaţă Publishing House: Braşov, Romania, 2008; pp. 335-336.

22. Marogel-Popa, T.; Cheța, M.; Marcu, M.V.; Dută, C.I.; Ioraș, F.; Borz, S.A. Manual cultivation operations in poplar stands: A characterization of job difficulty and risks of health impairment. Int. J. Environ. Res. Public Health 2019, 16, 1911. [CrossRef]

23. Zar, J.H. Biostatistical Analysis, 5th ed.; Pearson Prentice-Hall: Upper Saddle River, NJ, USA, 2010.

24. Karhu, O.; Kansi, P.; Kuorinka, I. Correcting working postures in industry: A practical method for analysis. Appl. Ergon. 1977, 8, 199-201. [CrossRef]

25. Björheden, R.; Apel, K.; Shiba, M.; Thompson, M. IUFRO Forest Work Study Nomenclature; The Swedish University of Agricultural Science: Garpenberg, Sweden, 1995.

26. Corella-Justavino, F.; Jimenez Ramirez, R.; Meza Perez, N.; Borz, S.A. The use of OWAS in forest operations postural assessment: Advantages and limitations. Bull. Transilv. Univ. Braşov Ser. II For. Wood Ind. Agric. Food Eng. 2015, 8, 7-16.

27. Zanuttini, R.; Cielo, P.; Poncino, D. The OWAS method. Preliminary results for the evaluation of the risk of work-related musculo-skeletal disorders (WMSD) in the forestry sector in Italy. For. Riv. Selvic. Ecolog. For. 2005, 2, 242-255.

28. Borz, S.A.; Talagai, N.; Cheța, M.; Chiriloiu, D.; Gavilanes Montoya, A.V.; Castillo Vizuete, D.D.; Marcu, M.V. Physical strain, exposure to noise and postural assessment in motor-manual felling of willow short rotation coppice: Results of a preliminary study. Croat. J. For. Eng. 2019, 40, 377-388. [CrossRef]

29. Cheţa, M.; Marcu, M.V.; Borz, S.A. Workload, exposure to noise, and risk of musculoskeletal disorders: A case study of motor-manual tree felling and processing in poplar clear cuts. Forests 2018, 9, 300. [CrossRef]

30. Spinelli, R.; Aminti, G.; de Francesco, F. Postural risk assessment of firewood processing. Ergonomics 2016, 60, 1-9. [CrossRef] 
31. Spinelli, R.; Aminti, G.; Magagnotti, N.; De Francesco, F. Postural risk assessment of small-scale debarkers for wooden post production. Forests 2018, 9, 111. [CrossRef]

32. Calvo, A. Musculoskeletal disorders (MSD) risks in forestry: A case study to propose an analysis method. Agric. Eng. Int. 2009, 11, 1-9.

33. Comper, M.L.C.; Dennerlein, J.T.; dos Santos Evangelista, G.; da Silva, P.R.; Padula, R.S. Effectiveness of job rotation for preventing work-related musculoskeletal diseases: A cluster randomized controlled trial. Occup. Environ. Med. 2017, 74, 543-544. [CrossRef] [PubMed]

34. Aragón-Vásquez, A.Y.; Silva-Lugo, E.D.; Nájera-Luna, J.A.; Méndez-González, J.; Hernández, F.J.; de la Cruz-Carrera, R. Postural analysis of the forestry worker in sawmills of El Salto, Durango, Mexico. Madera Bosques 2019, 25, e2531904.

35. Mathiassen, S.E. Diversity and variation in biomechanical exposure: What is it, and what would we like to know? Appl. Ergon. 2006, 37, 419-427. [CrossRef] [PubMed]

36. Da Costa, B.R.; Vieira, E.R. Risk factors for work-related musculoskeletal disorders: A systematic review of recent longitudinal studies. Am. J. Ind. Med. 2010, 53, 285-353. [CrossRef] [PubMed]

37. Borz, S.A.; Ignea, G.; Vasilescu, M.M. Small gains in wood recovery rate when disobeying the recommended motor-manual tree felling procedures: Another reason to use proper technical prescriptions. Bioresources 2014, 9, 6938-6949. [CrossRef]

(C) 2020 by the authors. Licensee MDPI, Basel, Switzerland. This article is an open access article distributed under the terms and conditions of the Creative Commons Attribution (CC BY) license (http://creativecommons.org/licenses/by/4.0/). 